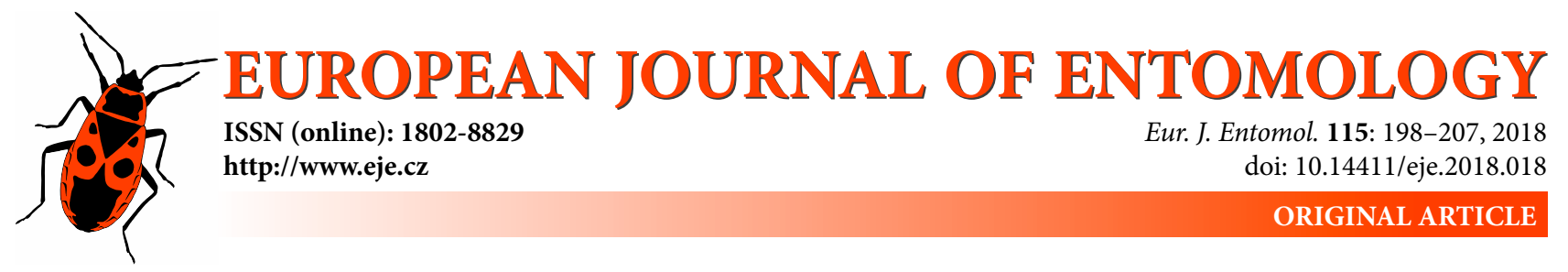

\title{
Cold hardiness of larvae of Dendrolimus tabulaeformis (Lepidoptera: Lasiocampidae) at different stages during the overwintering period
}

\author{
YuYing SHAO ${ }^{1}$, YuqIAN FENG ${ }^{1}$, Bin TIAN ${ }^{1}$, TAO WANG $^{2}$, YinghaO HE ${ }^{3}$ and ShixIANg ZONG ${ }^{1, *}$ \\ ${ }^{1}$ Beijing Key Laboratory for Forest Pest Control, Beijing Forestry University, Beijing 100083, P. R. China; \\ e-mails: zongsx@126.com,1102671261@qq.com, fengyuqian1988@163.com,363872410@qq.com \\ ${ }^{2}$ Mentougou Forestry Station, Beijing 102300, P. R. China; e-mail: 952330814@qq.com \\ ${ }^{3}$ School of Science, Beijing Forestry University, Beijing 100083, P. R. China; e-mail: 18811302553@163.com
}

Key words. Lepidoptera, Lasiocampidae, Dendrolimus tabulaeformis, larvae, supercooling point, cryoprotectants, cold hardiness

\begin{abstract}
The Chinese pine caterpillar Dendrolimus tabulaeformis is an important destructive leaf borer in boreal coniferous forests in China. This species overwinters in the larval stage. Changes in supercooling capacity and physiological-biochemical parameters of $D$. tabulaeformis larvae from a natural population were evaluated at different stages during the overwintering period. Cold hardiness of overwintering larvae collected in January was significantly greater than that of larvae collected in other months. January larvae survived for 15 days at $-10^{\circ} \mathrm{C}$ and for approximately 2 days at $-15^{\circ} \mathrm{C}$. By contrast, larvae collected in September survived for no more than $4 \mathrm{~h}$ at $-5^{\circ} \mathrm{C}$ and those in November and March no more than 1 day at $-15^{\circ} \mathrm{C}$. Supercooling point gradually decreased from $-5.9 \pm 0.3^{\circ} \mathrm{C}$ in September to a minimum of $-14.1 \pm 1.0^{\circ} \mathrm{C}$ in November, then gradually increased to the original value with the advent of spring. Water content gradually decreased from September to November, remained at approximately $74.5 \%$ until March and then gradually increased to levels similar to those in September. The lipid content gradually decreased from September to November, remained stable at approximately 3.2\% until March and then gradually increased to levels similar to those in September. Glycogen content increased to a peak in November and then decreased. The concentrations of several metabolites showed significant seasonal changes. The most prominent metabolite was trehalose with a seasonal maximum in November. Glucose levels were highest in January and then gradually decreased until in May they were at levels similar to those in September. Glycerol levels remained relatively stable during winter but increased significantly in May. This study indicates that $D$. tabulaeformis is a freeze-avoidant insect. Larvae increase their supercooling capacity by regulating physiological-biochemical parameters during overwintering. Our results provide the basis for further research into the mechanism of cold hardiness in this species.
\end{abstract}

\section{INTRODUCTION}

All stages of an insect's life cycle are affected by temperature. Low temperature is a key factor in insect growth and development and can impose strict limits on insect populations (Jing \& Kang, 2002; Wang \& Kang, 2014). To minimize the risk of damage by low ambient temperatures, overwintering insects often choose protected microhabitats such as the upper layer of soil, leaf litter or under snow, where temperature remains higher than air temperature (Lee, 1989; Danks, 2006; Feng et al., 2014). Insects also can adjust physiological-biochemical parameters to increase their supercooling capacity, thus enhancing their cold hardiness (Lee, 1989; Storey \& Storey, 1991). The degree of cold hardiness effects on not only the survival, reproduction and spread of an insect population, but also population density the following year (Liu, 1963; Jing \&
Kang, 2002). Cold hardiness essentially refers to the ability of insects to survive long- or short-term exposure to low temperatures (Lee, 1989). Therefore, survival at low temperatures is a good indicator of cold hardiness, which is thought to be closely related to the supercooling point (SCP) of a species, which is the lower temperature at which it dies (Lee \& Denlinger, 1985; Hao \& Kang, 2004; Jing \& Kang, 2004). The supercooling point is an important indicator of the cold hardiness and overwintering strategy of an insect (Bale, 1996; Jing \& Kang, 2002; Feng et al., 2016). In addition, previous research indicates that insect cold hardiness is closely connected with changes in many parameters such as water, lipid and glycogen content (Bale, 2002; Wang et al., 2011; Feng et al., 2015). Many cold-hardy insects produce and accumulate low molecular weight metabolites to increase their supercooling capac-

\footnotetext{
* Corresponding author; e-mail: zongsx@126.com
} 
ity (decrease SCP), thereby enhancing their cold hardiness (Lee, 1991; Storey \& Storey, 1991; Bale, 2002; Chen et al., 2010).

The Chinese pine caterpillar, Dendrolimus tabulaeformis (Lepidoptera: Lasiocampidae), is an important defoliator of coniferous forests in northern China (Liu, 1963; Zeng et al., 2010; Li, 2013). The frequent outbreaks of D. tabulaeformis are characterized by sudden population growth and rapid spread, resulting in significant damage to forests (Li, 2014). The caterpillar can seriously reduce the growth of Pinus tabulaeformis, which result in very serious economic losses in the provinces of Shanxi, Heilong Jiang and Liaoning in China (Zhu et al., 1995; Liu, 2006; Li, 2008). P. tabulaeformis plantations are simple, monocultural ecosystems, which are more likely to have low resistance to pests and may suffer considerable insect damage (Zhao, 2003; Liu et al., 2010). Pest control is therefore an essential aspect of the afforestation and cultivation of $P$. tabulaeformis.

Previous research on $D$. tabulaeformis have examined fundamental aspects of its biology and ecology, comprehensive prevention and control technology, and genetic diversity and pheromones (Liu, 1963; Xia et al., 1989, 1990; Wang \& Wang, 2006; Xue et al., 2006; Fan et al., 2008; Yuan et al., 2008; Zhang, 2011; Liu, 2012). This species has one generation per year and overwinters at the base of trunks of trees as fourth- or fifth-instar larvae (Tang, 2012). The supercooling point of overwintering larvae of D. tabulaeformis has been measured by Xia et al. (1993) and Zeng et al. (2008). Zeng et al. (2008) have also measured survival at $-14^{\circ} \mathrm{C}$ and larval metabolic rate associated with cold acclimation and de-acclimation, larval mortality and changes in the concentration of low molecular weight sugars, and conclude that $D$. tabulaeformis is a chill tolerant insect, depressing SCP by accumulating low molecular weight sugars. However, to date, the mechanism of cold hardiness in D. tabulaeformis larvae has not been studied systematically.

We based our research on the hypothesis that the supercooling capacity and physiological-biochemical parameters of overwintering larvae of D. tabulaeformis would be affected by changes in ambient temperature. This study aimed to investigate the following three issues: (i) the effect of ambient temperature on the supercooling capacity of larvae of D. tabulaeformis; (ii) changes in larval fresh mass (FM), water, lipid and glycogen content during the overwintering period; (iii) changes in the concentrations of low molecular weight metabolites in overwintering larvae. This study provides a quantitative basis for identifying the mechanisms of cold hardiness in overwintering larvae of D. tabulaeformis. It will help to predict outbreaks and range expansion, and contribute to the development of an effective way of controlling this insect.

\section{MATERIALS AND METHODS}

\section{Insect collection and environmental temperature}

Overwintering larvae of $D$. tabulaeformis were collected every 2 months between September 2014 and May 2015 from a $P$.

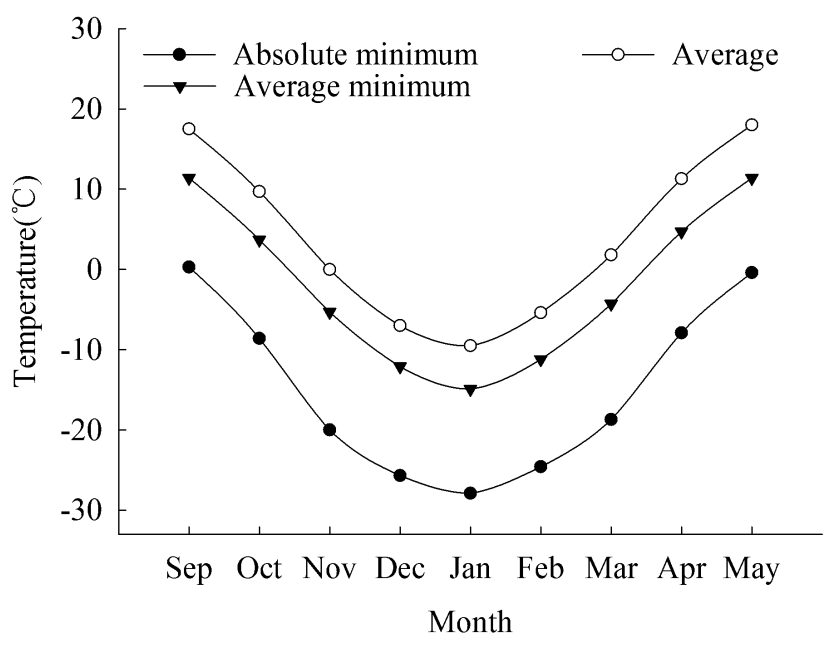

Fig. 1. Seasonal trends in mean monthly temperature $\left({ }^{\circ} \mathrm{C}\right)$, absolute minimum monthly temperature $\left({ }^{\circ} \mathrm{C}\right)$ and mean minimum monthly temperature $\left({ }^{\circ} \mathrm{C}\right.$ ) recorded at the location (Jianping County of Liaoning Province) where the larvae of $D$. tabulaeformis were collected.

tabulaeformis plantation in Jianping County, Liaoning Province, northeastern China. Approximately 300-500 larvae were collected on each occasion. Larvae were transported to the laboratory in Beijing within $48 \mathrm{~h}$ in conditions matching those at the sampling site, including sufficient leaves of $P$. tabulaeformis for normal feeding and then stored outdoors overnight. Without any treatment, healthy larvae were randomly selected the following morning for determination of different indicators.

Environmental temperature data from a nearby weather station were used as a proxy for the conditions at the sampling site. Data were downloaded from China Meteorological Data (http://www. cma.gov.cn/).

\section{Percentage survival at low temperatures}

To measure percentage survival larvae were collected in September, November, January and March and exposed to low temperatures. Ten larvae were selected for each treatment combination of low temperature and duration of exposure. Each treatment combination was replicated three times and percentage larval survival was the mean of the three replicates. The experimental temperature-duration combinations are shown in Table 1 and Fig. 1. The experimental temperatures were selected at intervals of $5^{\circ} \mathrm{C}$ or $10^{\circ} \mathrm{C}$ below the upper critical temperature, which was determined by the surface temperature recorded in Jianping County. The experimental exposure times were $4 \mathrm{~h}$ and 1, 2, 7 and 15 days. Larvae were removed from the refrigerator and placed at room temperature for $48 \mathrm{~h}$ after each experimental treatment (Feng et al., 2016). Larvae were examined for body movement in response to stimulation with a needle and the number of survivors was recorded (Ma et al., 2006).

Table 1. Combinations of low-temperature treatments and durations of exposure to them during successive stages in the overwintering period used in this study.

\begin{tabular}{|c|c|c|c|}
\hline \multirow{2}{*}{$\mathrm{T}$} & \multicolumn{3}{|c|}{ Overwintering stages } \\
\hline & September & - November & January \\
\hline $\begin{array}{l}0^{\circ} \mathrm{C} \\
-5^{\circ} \mathrm{C} \\
-10^{\circ} \mathrm{C} \\
-15^{\circ} \mathrm{C} \\
-20^{\circ} \mathrm{C} \\
-30^{\circ} \mathrm{C}\end{array}$ & $\begin{array}{l}1 d \\
1 d \\
1 d \\
1 d \\
1 d \\
1 d\end{array}$ & $\begin{array}{l}4 h 1 d 2 d \\
4 h 1 d 2 d \\
4 h 1 d \\
4 h\end{array}$ & $\begin{array}{l}4 h 1 d 2 d 7 d 15 d 1 d 2 d 7 d 15 d \\
4 h 1 d 2 d 7 d 15 d 1 d 2 d \\
4 h\end{array}$ \\
\hline
\end{tabular}

$\mathrm{T}$ - temperature; $\mathrm{h}$ - hour; $\mathrm{d}-$ day. 


\section{Determination of supercooling point (SCP)}

Supercooling points were determined using previously reported methods (Ouyang et al., 2011; Feng et al., 2016). Thirty to forty larvae were sampled randomly each month (September, November, January, March and May). Larval SCP was measured using a thermocouple, freezer and SCP automatic recorder. Larvae were attached to the thermocouple probe using parafilm, and the thermocouple with attached larva was enclosed in absorbent cotton to ensure a gradual reduction in the body temperature of the larva. Then the larva was placed in a freezer (High-low Temperature Test Chamber, GDW-100; YaShiLin, Beijing, China) and cooled to $-30^{\circ} \mathrm{C}$ at $1{ }^{\circ} \mathrm{C} \mathrm{min}^{-1}$. Changes in larval body temperature were recorded using a data recorder (uR100, Model 4152, Yokogawa Electric Co., Seoul, Korea) and displayed on a computer. Larval body temperature decreased in step with the decrease in temperature inside the freezer. Because of the latent heat of crystallization of body fluid, a sudden increase in larval body temperature occurs and this inflection point was taken as the SCP.

\section{Determination of fresh mass (FM) and water content}

Between 30 and 40 larvae were selected randomly to determine FM and water content for each month sampled (September, November, January, March and May). After the FM measurement, larvae were placed individually in 2 or $5 \mathrm{ml}$ plastic tubes with walls previously perforated using an electric iron. Tubes were placed in a drying oven at $60^{\circ} \mathrm{C}$ for $48 \mathrm{~h}$ to achieve constant dry mass (DM). Larvae were weighed on an analytical balance (AB204-S; Metler-Toledo, Greifensee, Switzerland; to an accuracy of $0.0001 \mathrm{~g}$ ). Weight loss was used as a proxy for water content, calculated as follows: $(\mathrm{FM}-\mathrm{DM}) / \mathrm{FM}^{*} 100 \%$ (Ouyang et al., 2011; Feng et al., 2016).

\section{Determination of total lipid content}

The chloroform-methanol solution method was used for determining total lipid content (Folch et al., 1957). Ten larvae were selected at random in each of the months sampled (September, November, January, March, and May). After determining FM, each larva was placed in a 2 or $5 \mathrm{ml}$ plastic tube and oven-dried in order to determine DM. Larvae were then ground to a powder, mixed with a $4 \mathrm{ml}$ mixture of chloroform: methanol $=2: 1$ and centrifuged at $2600 \times \mathrm{g}$ for $10 \mathrm{~min}$. The supernatant was removed, and the procedure was repeated twice. Finally, the residue in the tube was oven-dried at $60^{\circ} \mathrm{C}$ for $48 \mathrm{~h}$ in order to determine the lipid free dry mass (LDM). Lipid content was calculated using the FM, DM and LDM, as follows: (DM-LDM) / DM * 100\%.

\section{Determination of total glycogen content}

Five to ten larvae were analyzed in each of the months sampled. After determining DM, $2 \mathrm{ml}$ of $70 \%(\mathrm{v} / \mathrm{v})$ ethanol (containing $10 \mu \mathrm{l}$ erythrose as the internal standard) was added to each tube, ground into an homogenate with the larva and centrifuged at $2600 \times \mathrm{g}$ for $10 \mathrm{~min}$. The supernatant was removed, and the procedure was repeated twice (Liu et al., 2007). Following the addition of $2 \mathrm{ml} 10 \%(\mathrm{v} / \mathrm{v})$ trichloroacetic acid, the mixture was heated to $80^{\circ} \mathrm{C}$ for $15 \mathrm{~min}$, then cooled and centrifuged at $2600 \times \mathrm{g}$ for $10 \mathrm{~min}$. The supernatant $(0.5 \mathrm{ml})$ was mixed with $0.5 \mathrm{ml}$ phenol (5\%) and $2.5 \mathrm{ml}$ concentrated sulphuric acid. After standing for $10 \mathrm{~min}$, the mixture was shaken, heated for $20 \mathrm{~min}$ at $75^{\circ} \mathrm{C}$, cooled, and diluted to $15 \mathrm{ml}$ (Ouyang et al., 2011; Feng et al., 2016). Absorbance at $490 \mathrm{~nm}$ was read using an ultraviolet (UV)-visible spectrophotometer (TU-1810; Puxin, Beijing, China). Results were compared with a glycogen standard curve to obtain the glycogen content of the samples.

\section{Analysis of low molecular weight metabolites}

Low molecular weight metabolites were analyzed using gas chromatography and 10 larvae each month (Ouyang et al., 2011; Feng et al., 2016). After determining DM the larvae were ground into an homogenate with $0.4 \mathrm{ml} \mathrm{70 \%} \mathrm{(v/v)} \mathrm{ethanol} \mathrm{(containing} 10$ $\mu 1$ erythrose as the internal standard). The mixture was then centrifuged for $5 \mathrm{~min}$ at $10,000 \times \mathrm{g}$, and the supernatant was placed in a clean tube and dried in a stream of nitrogen at $40^{\circ} \mathrm{C}$ in a derivatization vial. The residue was dissolved in pyridine and placed in an ice-water bath for $30 \mathrm{~min}$ with hexamethyldisilazan and chlorotrimethylsilane to complete the silylation. After centrifugation for $5 \mathrm{~min}$ at $10,000 \times \mathrm{g}, 1 \mathrm{ml}$ of the mixture was inserted into a Gas Chromatography Detector (Agilent 7890 GC; Agilent, Japan), consisting of a split-less capillary injector, a flame ionization detector and an HP 3394 integrator. The carrier gas was nitrogen $\left(30 \mathrm{ml} \mathrm{min}{ }^{-1}\right)$ with the initial temperature kept at $180^{\circ} \mathrm{C}$ for $20 \mathrm{~min}$, then increased to $280^{\circ} \mathrm{C}$ at a rate of $10^{\circ} \mathrm{C} \mathrm{min}{ }^{-1}$ and kept for $10 \mathrm{~min}$. Composition and concentrations of low molecular weight metabolites were determined by comparison with the retention time, peak time and area of standards at five different concentrations $\left(1.0,0.5,0.25,0.125\right.$, and $\left.0.0625 \mathrm{mg} \mathrm{ml}^{-1}\right)$.

\section{Statistical analysis}

Analysis of variance (ANOVA) and least significant difference (LSD) multiple comparisons (with statistical significance set at $\mathrm{P}<0.05$ ) were used to test the effects of environmental temperature at different stages during the overwintering period on SCP and the physiological-biochemical parameters (FM, water content, glycogen content, lipid content and low molecular weight metabolites). Data analysis was performed using the SPSS 16.0 statistical software package, with the results plotted in Sigma Plot 12.5.

\section{RESULTS}

\section{Environmental temperature}

Seasonal trend in the environmental temperature is shown in Fig. 1. The mean monthly temperature decreased gradually from $17.5^{\circ} \mathrm{C}$ in September to $-9.5^{\circ} \mathrm{C}$ in January, before increasing to $18^{\circ} \mathrm{C}$ in May. The mean minimum monthly temperature decreased gradually from $11.4^{\circ} \mathrm{C}$ in September to $-14.9^{\circ} \mathrm{C}$ in January, before increasing to $11.4^{\circ} \mathrm{C}$ in May. During the winter, the lowest temperature $\left(-27.9^{\circ} \mathrm{C}\right)$ was recorded in January.

\section{Percentage survival at low temperatures}

Percentage survival of larvae at low temperatures in different months are shown in Fig. 2.

In September the percentage survival declined with decreasing temperature when larvae were exposed to low temperatures for 1 day. The percentage survival decreased to $70.0 \%$ after 1 day of exposure to $-10^{\circ} \mathrm{C}$, and larvae could not survive at temperatures below $-15^{\circ} \mathrm{C}$. After exposure to $-5^{\circ} \mathrm{C}$ for 4 days, the percentage survival decreased to zero.

In November the percentage survival was nearly $100 \%$ at $0^{\circ} \mathrm{C}$ and $-5^{\circ} \mathrm{C}$, until the period of exposure was extended to 2 days. The percentage survival decreased to $90.0 \% \pm$ $5.8 \%$ at $-15^{\circ} \mathrm{C}$ after $4 \mathrm{~h}$ of exposure, and decreased further to zero after 1 day of exposure to $-15^{\circ} \mathrm{C}$. As the temperature decreased to $-20^{\circ} \mathrm{C}$, all the larvae died.

In January the percentage survival was nearly $100 \%$ at $-10^{\circ} \mathrm{C}$ until the period of exposure was extended to 15 

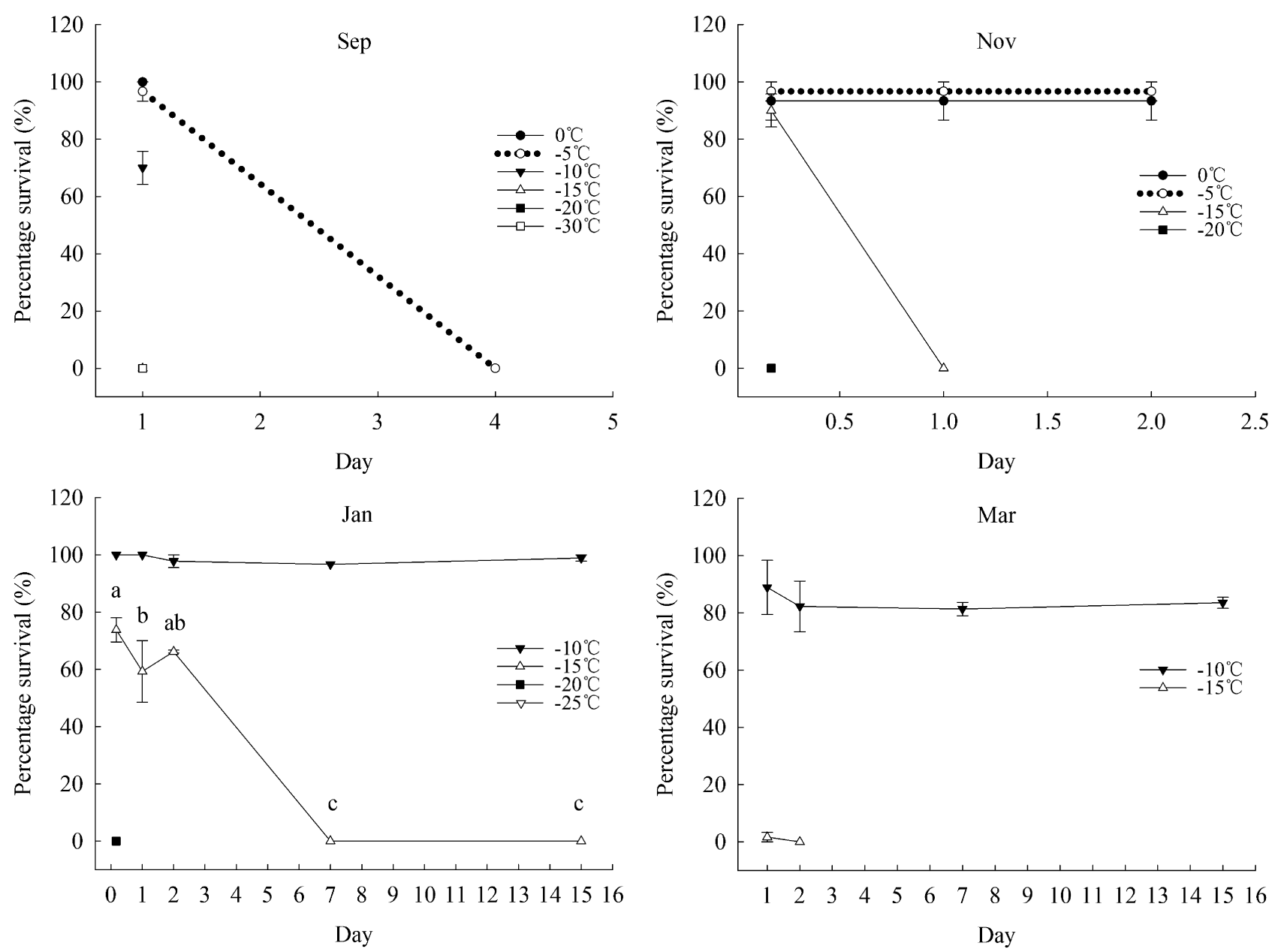

Fig. 2. Percentage survival of larvae of $D$. tabulaeformis over time at different temperatures. Each graph shows the results of different temperature-duration treatments in a particular month of the overwintering period. Data points are means or means \pm SE values of three replicate groups $(n=10)$ of larvae. Different lower case letters indicate significant differences at $P<0.05$.

days. A significant difference was detected in the percentage survival of overwintering larvae exposed to $-15^{\circ} \mathrm{C}$ for different periods of time $(\mathrm{F}=119.455$; $\mathrm{df}=4,14$; $\mathrm{P}<0.001)$. Percentage survival at $-15^{\circ} \mathrm{C}$ decreased from $59.2 \% \pm 6.2 \%$ after 1 day of exposure to zero after 7 days. Larvae did not survive temperatures below $-20^{\circ} \mathrm{C}$.

In March percentage survival was between $80.0 \%$ and $90.0 \%$ at $-10^{\circ} \mathrm{C}$, with a minimum value of $81.3 \% \pm 2.3 \%$. Percentage survival was $1.7 \% \pm 1.7 \%$ at $-15^{\circ} \mathrm{C}$ after just 4 $\mathrm{h}$ of exposure, so very few overwintering larvae survived at $-15^{\circ} \mathrm{C}$.

Overall, the percentage survival of overwintering larvae collected in January and March was significantly higher than that of larvae collected in September and November. The January larvae survived at $-10^{\circ} \mathrm{C}$ for 15 days and survived for approximately 2 days at $-15^{\circ} \mathrm{C}$. The percentage survival of larvae in September decreased gradually at $-5^{\circ} \mathrm{C}$ and in November larvae did not survive more than 1 day at $-15^{\circ} \mathrm{C}$.

\section{Supercooling point (SCP)}

Significant monthly differences were detected in SCP (F $=35.415 ; \mathrm{df}=4,157 ; \mathrm{P}<0.001$ ) (Fig. 3). The SCP followed the same trend as the seasonal changes in ambient temperature. Mean SCPs of larvae in September $(-5.9 \pm$ $0.3^{\circ} \mathrm{C}$ ) and May $\left(-5.4 \pm 0.5^{\circ} \mathrm{C}\right)$ were higher than in the other months. Mean SCPs of larvae in November $(-14.1$ $\left.\pm 1.0^{\circ} \mathrm{C}\right)$ and January $\left(-13.7 \pm 0.7^{\circ} \mathrm{C}\right)$ were significantly lower than the values recorded in the other months (Fig. 3).

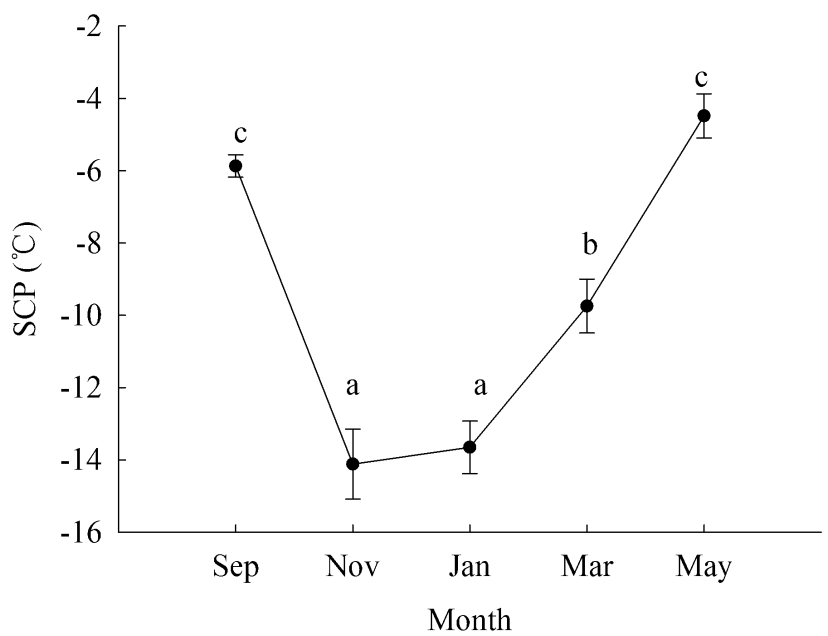

Fig. 3. Supercooling point (SCP) of larvae of D. tabulaeformis recorded in particular months during the overwintering period. Data points are means \pm SE of 30 replicate larvae. Different lower case letters indicate significant differences at $P<0.05$. 


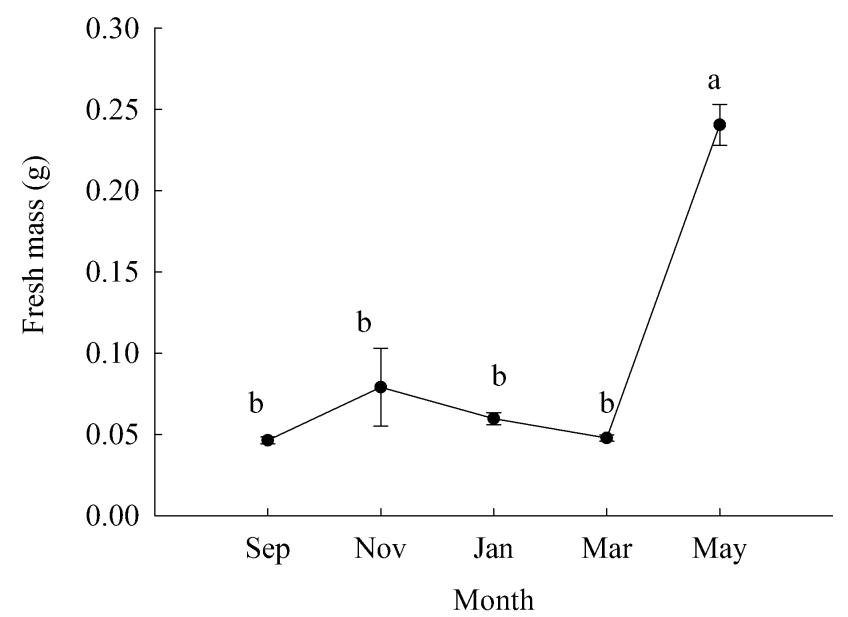

Fig. 4. Fresh mass of larvae of $D$. tabulaeformis recorded in particular months during the overwintering period. Data points are means \pm SE of 10 replicate larvae. Different lower case letters indicate significant differences at $P<0.05$.

\section{Fresh mass (FM)}

Significant monthly differences were detected in FM (F $=32.862 ; \mathrm{df}=4,166 ; \mathrm{P}<0.001)$ (Fig. 4). Fresh mass increased slightly from September to November, with a small peak value of $0.08 \pm 0.02 \mathrm{~g}$ recorded in November. Fresh mass then decreased to the minimum value of $0.05 \pm 0.00$ $\mathrm{g}$ in March. A significant increase was then recorded from March to May, with a maximum value of $0.24 \pm 0.00 \mathrm{~g}$ in May.

\section{Water content}

Water content differed significantly $(\mathrm{F}=65.66$; $\mathrm{df}=4$, 166; $\mathrm{P}<0.001$ ) among the months (Fig. 5). The water content decreased from September to November, then remained stable from November to January, before increasing to the highest level in May. Water content in September $(80.1 \% \pm 0.4 \%)$ and May $(82.8 \% \pm 0.3 \%)$ were higher than in the other months. No significant differences were detected in the water content in November, January and

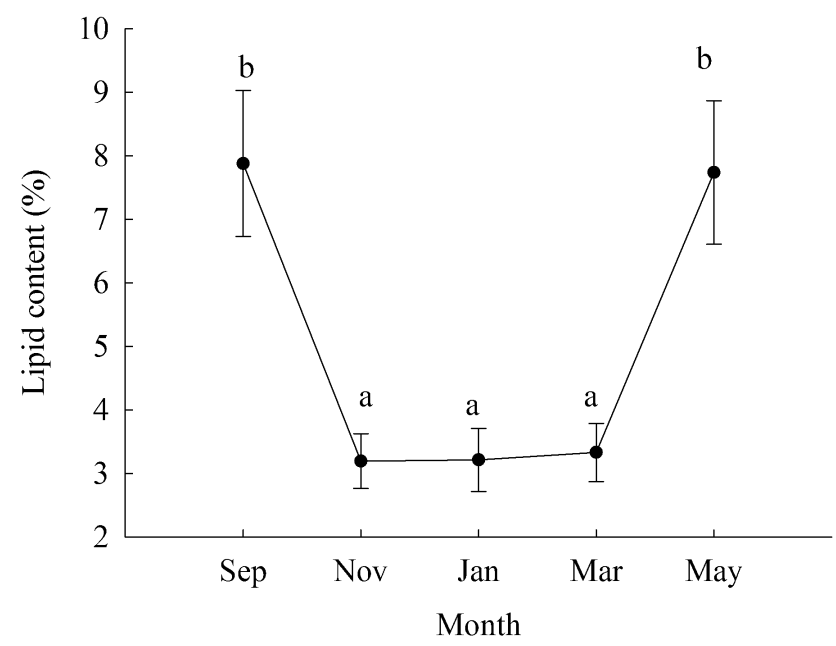

Fig. 6. Lipid content of larvae of $D$. tabulaeformis recorded in particular months during the overwintering period. Data points are means $\pm S E$ of 10 replicate larvae. Different lower case letters indicate significant differences at $P<0.05$.

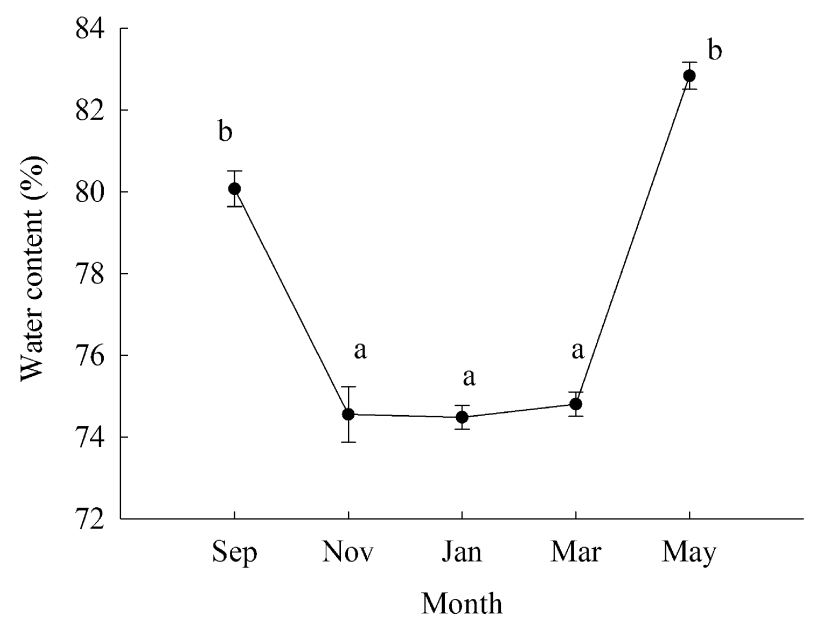

Fig. 5. Water content of larvae of $D$. tabulaeformis recorded in particular months during the overwintering period. Data points are means \pm SE of 10 replicate larvae. Different lower case letters indicate significant differences at $\mathrm{P}<0.05$.

March. The minimum value of $74.5 \% \pm 0.3 \%$ was recorded in January.

\section{Lipid content}

Significant monthly differences were detected in lipid content $(\mathrm{F}=9.528$; $\mathrm{df}=4,44 ; \mathrm{P}<0.001)$ (Fig. 6). Similar to the pattern in water content, lipid content decreased from September to November, remained stable from November to January and then increased. Lipid contents in September $(7.9 \% \pm 1.2 \%)$ and May $(7.7 \% \pm 1.1 \%)$ were higher than in the other months. No significant differences were recorded in the lipid content values in November, January and March (about 3.2\%).

\section{Glycogen content}

Significant monthly differences were detected in glycogen content $(\mathrm{F}=9.528$; $\mathrm{df}=4,44 ; \mathrm{P}<0.001)$ (Fig. 7). Glycogen content increased from September to November, then decreased from November to May. The maximum

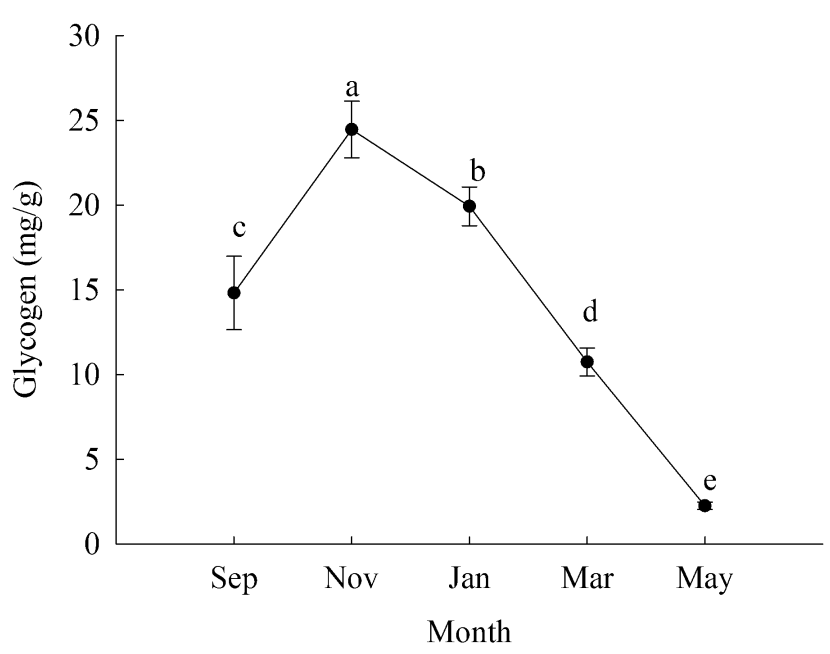

Fig. 7. Total glycogen content of larvae of $D$. tabulaeformis recorded in particular months during the overwintering period. Data points are means \pm SE of 10 replicate larvae. Different lower case letters indicate significant differences at $P<0.05$. 

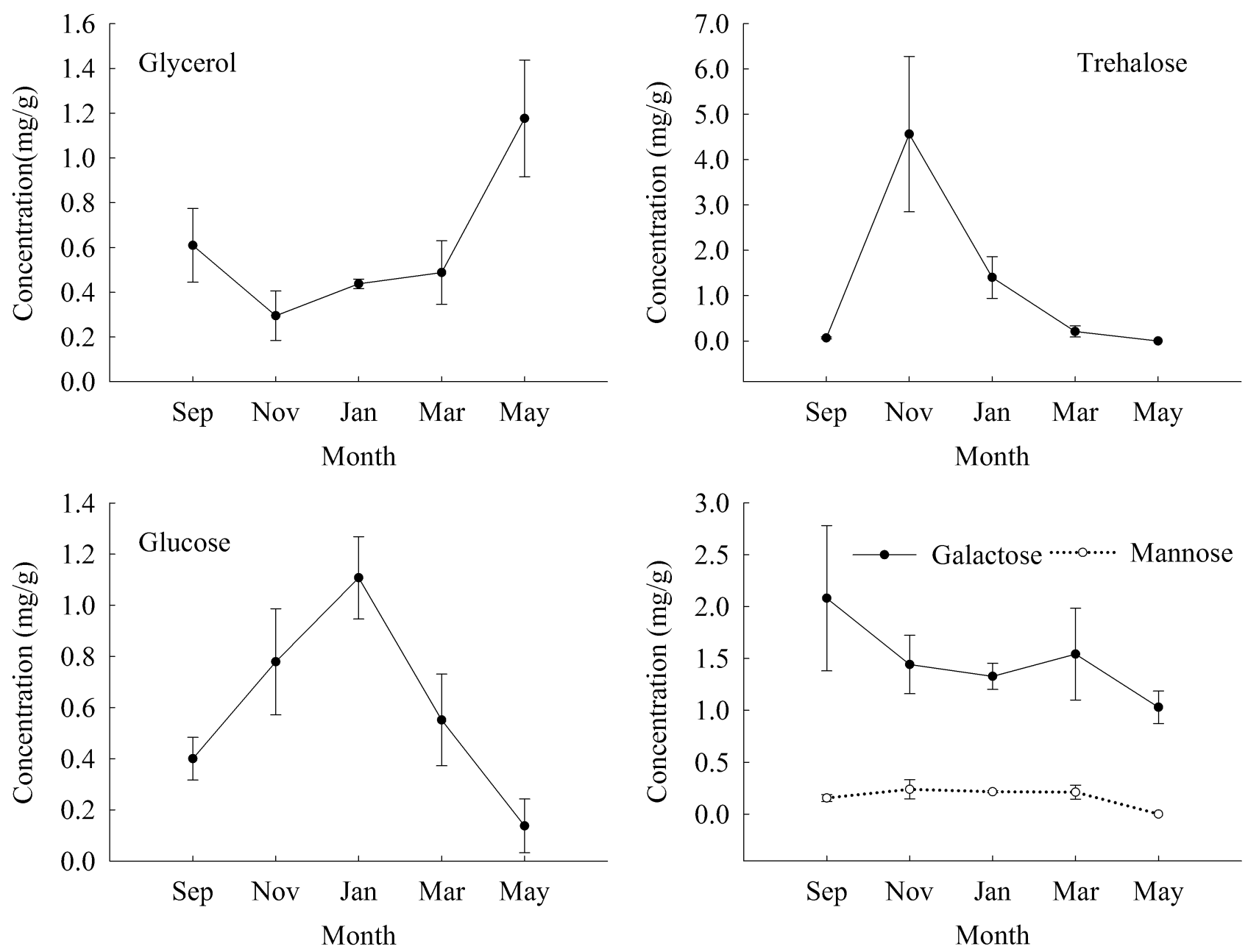

Fig. 8. Low molecular weight metabolite contents (glycerol, glucose, trehalose, galactose, mannose) of larvae of $D$. tabulaeformis recorded in particular months during the overwintering period. Data points are means \pm SE of three replicate larvae. Different lower case letters indicate significant differences at $\mathrm{P}<0.05$.

value $\left(24.46 \pm 1.67 \mathrm{mg} \mathrm{g}^{-1}\right)$ was recorded in November and the minimum value $\left(2.26 \pm 0.22 \mathrm{mg} \mathrm{g}^{-1}\right)$ in May.

\section{Concentration of low molecular weight metabolites}

Three low molecular weight metabolites in the body of larvae were identified as cryoprotectants: glycerol, glucose and trehalose (Fig. 8). The levels of all three compounds changed significantly during the overwintering period $\left(\mathrm{F}_{\text {glycerol }}=4.534, \mathrm{df}=4,10, \mathrm{P}=0.024 ; \mathrm{F}_{\text {glucose }}=5.724, \mathrm{df}=\right.$ $\left.4,10, \mathrm{P}=0.012 ; \mathrm{F}_{\text {trehalose }}=5.946, \mathrm{df}=4,10, \mathrm{P}=0.010\right)$. The glycerol concentration showed no significant change from September to March but increased to a maximum in May $\left(1.18 \pm 0.26 \mathrm{mg} \mathrm{g}^{-1}\right)$. Minimum and maximum glucose concentrations were recorded in May $(0.14 \pm 0.11 \mathrm{mg}$ $\left.\mathrm{g}^{-1}\right)$ and January $\left(1.11 \pm 0.16 \mathrm{mg} \mathrm{g}^{-1}\right)$, respectively. After an initial sharp increase, the concentration of trehalose decreased significantly. Maximum trehalose concentration was recorded in November $\left(4.56 \pm 1.71 \mathrm{mg} \mathrm{g}^{-1}\right)$ and the minimum value $\left(1.40 \pm 0.46 \mathrm{mg} \mathrm{g}^{-1}\right)$ in January. The trehalose concentration in the other months was $<0.20$ $\mathrm{mg} \mathrm{g}^{-1}$. Overall, during the overwintering period, the concentrations of trehalose and glucose increased, whereas the concentrations of glycerol, galactose and mannose did not differ significantly.

\section{DISCUSSION}

\section{Overwintering strategies}

Our results indicate that the low temperatures experienced while overwintering enhance the cold hardiness of D. tabulaeformis larvae. Exposed to the same experimental low temperatures $\left(-15^{\circ} \mathrm{C}\right)$, percentage survival of larvae collected in September and March were obviously lower than in November and January. As the environmental temperature decreased, the critical temperature that larvae could endure also decreased, and the time for which they survived increased. These larval reactions may be related to cold acclimation during the overwintering period or to the influence of reduced metabolism during diapause, which enable larvae to survive cold winters (Danks, 1987; Zhang, 2005).

The relationship between freezing and overwintering mortality defines three categories of insects: freeze-tolerant, freeze-avoidant and chill-susceptible (Lee, 1991; Bale, 2002; Sinclair et al., 2003; Lee, 2010; Sinclare et al., 2015). Freeze-tolerant insects are able to survive the freezing of extracellular fluid, and typically have a poor supercooling capacity with high SCPs (Lee, 1991, 2010; Bale, 2002; Sinclare et al., 2015). Freeze-avoidant insects 
are able to supercool their body fluids but die immediately their body fluids freeze, while chill-susceptible insects die due to exposure to cold rather than freezing (Lee, 2010; Sinclare et al., 2015). Generally, insects improve their cold hardiness by lowering their SCP to a level below the ambient temperature during the overwintering period, thereby ensuring that the body fluids remain unfrozen (Crosthwaite et al., 2011). In the present study, as ambient temperature varied, there were significant changes in SCP at different stages during the overwintering period. In addition, the mean SCPs of D. tabulaeformis larvae measured in different months during the overwintering period were lower than the mean ambient temperature, suggesting that the larvae might remain unfrozen throughout the winter. Overwintering larvae collected in the field were all in an unfrozen state, and in our exposure experiments the freezing of body fluids led directly to the death of larvae. The relationship between SCP and percentage survival can be used to identify the larval survival strategy. Our results indicate that, in the coldest month, January, the percentage survival at $-15^{\circ} \mathrm{C}$ decreased to $59.2 \% \pm 6.2 \%$ after 1 day, and decreased to zero after a 7 day exposure. Larvae therefore cannot survive at $-15^{\circ} \mathrm{C}$ in January as the SCP of $-13.7 \pm 0.7^{\circ} \mathrm{C}$ is slightly higher than $-15^{\circ} \mathrm{C}$. Similar results were obtained in November and March. In November, the SCP $\left(-14.1 \pm 1.0^{\circ} \mathrm{C}\right)$ was slightly higher than the exposure temperature $\left(-15^{\circ} \mathrm{C}\right)$ for 1 day, a combination for which the percentage survival was zero. In March, the SCP $\left(-9.8 \pm 0.7^{\circ} \mathrm{C}\right)$ was substantially higher than the exposure temperature $\left(-15^{\circ} \mathrm{C}\right)$ for 1 day, for which the percentage survival was $1.7 \% \pm 1.7 \%$. These results indicate that the larvae had a strong supercooling capacity and could resist the stress of low temperatures during the overwintering period. This allows us to infer that $D$. tabulaeformis uses a freeze-avoidance strategy during the overwintering period.

\section{Internal physiological-biochemical parameters}

Insect cold hardiness is not only related to ecological adaptability but depends directly on complex changes in physiological-biochemical parameters within an insect's body, for example the contents of water, lipid and glycogen (Zachariassen et al., 1985; Storey \& Storey, 1991; Li \& Gong, 2000; Saeidi et al., 2012; Feng et al., 2014). Our results demonstrate that there are different trends in FM and water content during the overwintering period. A small increase in FM from September to November was detected and we speculated that this may be due to continuous feeding from September to November, which enabled some growth and development before winter. In addition, the overall decline in FM from November to March may be due to the consumption of energy reserves, such as glycogen (Feng et al., 2016). The water content remained at a low level from November to March, compared with the values in September and May. Changes in water content were consistent with the trends recorded in overwintering larvae of Diaphania pyloalis (Han et al., 1989; Chen et al., 2005). The reduced water content and high cryoprotectant concentrations (e.g., low molecular weight metabolites and antifreeze protein) increase the concentration of insect body fluids, thus enhancing their supercooling capacity (Ouyang \& Ge, 2014). There was a close correlation between water content and percentage survival. Water contents from September to March followed a similar trend to percentage survival, which directly reflected supercooling capacity. Our results show an enhanced supercooling capacity from September to March, which was confirmed by the increased percentage survival at $-10^{\circ} \mathrm{C}$ (from $70 \%$ in September to $100 \%$ in January and $90 \%$ in March) and at $-15^{\circ} \mathrm{C}$ (from zero in September to $90 \%$ in November and $70 \%$ in January). As ambient temperature rises in spring, the larvae climb trees and resume eating and the water content increases substantially by May. Typically, insects decrease their water content in winter to increase the concentration of solutes, which in turn increases their supercooling capacity (Han et al., 1989; Holmstrup, 1992; Sun et al., 2001; Danks, 2006; Feng et al., 2014).

Larval metabolism changed significantly during the overwintering period as the primary ergastic substance, total lipid content, decreased significantly from November to March. Similar trends in lipid content are recorded in Harmonia axyridis and Carposina niponensis (Zhang et al., 2007; Zhao et al., 2008). We suggest that this significant decline may be related to the consumption of lipids in winter and the partial conversion of free lipids to structural lipids and free fatty acids in order to promote larval cold hardiness (Chen et al., 2005). Lipid content may be overestimated by the chloroform-methanol method, which may extract structural lipids and other nonpolar compounds (Williams et al., 2011). The clear increase in larval lipid content in spring may be caused by the co-extraction of glycerol. In contrast to total lipids, glycogen content increased in the pre-overwintering months, then decreased later in the overwintering period, with the highest level recorded in November. The accumulation of glycogen from September to November may be due to the sustained feeding before overwintering, such that levels peaked in November. As ambient temperature falls, the overwintering larvae undergo cold acclimation during which glycogen is gradually converted to polyols and sugars, such as glucose and trehalose to promote cold hardiness (Sun et al., 2001; Andreadis \& Athanassiou, 2017).

Previous studies report that many insects develop a multicomponent cryoprotectant system, principally made up of sorbitol, glucose, glycerol, mannose and trehalose (Sømme, 1982; Han et al., 2005). Cryoprotectants that accumulated in winter also play an important role in increasing the content of bound water and maintaining the stability of biological systems (Denlinger, 1991; Feng et al., 2014). In the present study, overwintering larvae showed significant changes in their content of low molecular weight metabolites, in particular glucose, glycerol and trehalose. Glucose content increased significantly as ambient temperature decreased, reaching a maximum value in January. Trehalose showed a similar pattern to glycogen, with highest levels in November. Previous research shows that glucose and trehalose may be accumulated as cryoprotectants, increasing body fluid concentration in order 
to protect the insect from the effects of low temperatures experienced when overwintering (Han et al., 2005; Rozsypal et al., 2013; Sinclair et al., 2015). We also infer that glucose may increase as a result of glycogen breakdown by phosphorylase, after acclimation to low winter temperatures (Chen \& Denlinger, 1990). Previous studies indicate that trehalose, a non-reducing disaccharide combining two molecules of glucose, could promote larval cold hardiness by two mechanisms that maintain the stability of proteins: firstly, protecting the structure of biological membranes, and secondly, reducing the combination of proteins and sugar in the process of dehydration (Behm, 1997; Dai, 2006). As the main sugar in insect blood, trehalose plays an important role in energy metabolism, diapause and resistance and can be converted to glucose to provide energy (Feng et al., 2014; Qin et al., 2015). We also found that glucose concentrations increased steadily in midwinter when trehalose concentrations began to decrease. Therefore, we suggest that trehalose may be transformed into glucose, which has a more important role in cold-resistance during overwintering (Li et al., 2012). Previous work shows that glycerol in insects can decrease SCP, and protect biological membranes and proteins subjected to low-temperature stress (Stephen et al., 2001). In our results (Fig. 8), glycerol concentrations were much lower than glucose and trehalose, and did not change significantly during overwintering (from September to March), which indicates that glycerol had no effect on promoting the cold hardiness of D. tabulaeformis larvae (Wharton et al., 1984).

The cold hardiness of insects is related to SCP, and also to substances such as glycogen, lipids and low molecular weight metabolites (trehalose, glycerol, and glucose). Cold hardiness is also affected by other factors, such as the developmental stage (instars), site and duration of overwintering, which are all determined by long-term adaptation to the native environment (Wang et al., 2011). We measured the cold hardiness of $D$. tabulaeformis larvae at normal and stable ambient temperatures to establish the general rules governing cold hardiness in this species. We also analyzed changes in larval supercooling capacity and internal physiological-biochemical parameters. Processes of conversion between these substances in the bodies of overwintering larvae were inferred from previous studies. But the cold hardiness of the larvae of $D$. tabulaeformis at extremely low temperatures and their responses to different ranges of temperature were not studied. In conclusion, future research should focus on the following points: (i) changes in the content of protein and free amino acids during the overwintering period; (ii) the cold hardiness mechanism of larvae of D. tabulaeformis; (iii) the percentage survival and extreme low-temperature adaptability of larvae of $D$. tabulaeformis during the overwintering period; (iv) specific methods for reducing the cold hardiness of larvae of D. tabulaeformis.

ACKNOWLEDGEMENTS. This study was supported by Project for Forestry commonweal industry scientific Research Plan 201404401.

\section{REFERENCES}

AndReadis S.S. \& Athanassiou C.G. 2017: A review of insect cold hardiness and its potential in stored product insect control. - Crop. Prot. 91: 93-99.

BALE J.S. 1996: Insect cold hardiness: a matter of life and death.Eur. J. Entomol. 93: 369-382.

BALE J.S. 2002: Insects and low temperatures: from molecular biology to distributions and abundance. - Phil. Trans. R. Soc. (B) 357: 849-862.

Bенм C.A. 1997: The role of trehaelos in the physiology of nematodes. - Int. J. Parasitol. 27: 215-229.

Chen C.P. \& DenLinger D.L. 1990: Activation of phosphorylase in response to cold and heat stress in the flesh fly, Sarcophaga crassipalpis. - J. Insect Physiol. 36: 549-554.

Chen Y.J., Sun X.L., Zhang W.G., Mou Z.Z. \& Guo G.Z. 2005: Relationship between variation of water, lipid and glycerin in over-wintering Diaphania pyloalis Walker larvae and coldhardiness. - Sci. Sericult. 31: 111-116.

Chen H., Liang G.M., Zou L.Y., Guo F., Wu K.M. \& Guo Y.Y. 2010: Research progresses in the cold hardiness of insects. - Plant Prot. 36: 18-24.

Crosthwaite J.C., Sobek S., Lyons D.B., Bernards M.A. \& SinCLAIR B.J. 2011: The overwintering physiology of the emerald ash borer, Agrilus planipennis Fairmaire (Coleoptera: Buprestidae). - J. Insect Physiol. 57: 166-173.

Dai S.M., Cheng X.Y., XIAO Q.M. \& XIE B.Y. 2006: Research progress in nematode cold tolerance. - Acta Ecol. Sin. 26: 3885-3890.

DANKs H.V. 1987: Insect Dormancy: An Ecological Perspective. Biological Survey of Canada Press, Ottawa, pp. 114-122.

DANKs H.V. 2006: Insect adaptations to cold and changing environments. - Can. Entomol. 138: 1-23.

Denlinger D.L. 1991: Relationship between cold hardiness and diapause. In Lee R.E. et al. (eds): Insects at Low Temperature. Chapman \& Hall, New York, London, pp. 174-198.

FAN J.H., XIE Y.P., Xue J.L. \& Li B.Z. 2008: A strain of parasitic Dendrolimus tabulaeformis toxin chemical constituents of Beauveria bassiana. - Acta Microbiol. Sin. 48: 596-601.

FENG Y.Q., WANG J.L. \& ZoNG S.X. 2014: Review of insect overwintering stages and cold-resistance strategies. - Chin. Agr. Sci. Bull. 30: 22-25.

Feng Y.Q., Li W.B., Luo Y.Q., Wang T. \& Zong S.X. 2015: Cold tolerance of Asias halodendri (Pallas) overwintering larvae. - Acta Agric. Bor-Occid. Sin. 24: 175-180.

Feng Y.Q., Xu L.L., Li W.B., Xu Z.C., Cao M., Wang J.L., Tao J. \& ZoNG S.X. 2016: Seasonal changes in supercooling capacity and major cryoprotectants of overwintering Asian longhorned beetle (Anoplophora glabripennis) larvae. - Agr. For. Entomol. 18: 302-312.

Folch J., Lees M. \& Sloane Stanley G.H. 1957: A simple method for the isolation and purification of total lipids from animal tissues. - J. Biol. Chem. 226: 497-509.

HAN Z.J., WANG Y.C. \& You Z.P. 1989: Cold-hardiness mechanism of terrestrial insects. - Chin. Bull. Entomol. 1: 39-42.

Han R.D., Sun X.G., Xu Y.Y. \& Zhang W.G. 2005: The biochemical mechanism of cold-hardiness in overwintering larva of Dendrolimus spectabilis Butler (Lepidoptera: Lasiocampidae). - Acta Entomol. Sin. 25: 1352-1356.

HAO S.G. \& KANG L. 2004: Supercooling capacity and cold hardiness of the eggs of the grasshopper Chorthippus fallax (Orthoptera: Acrididae). — Eur. J. Entomol. 101: 231-236.

Holmstrup M. 1992: Cold hardiness strategy in cocoons of the lumbricid earthworm Dendrobaena octaedra (Savigny). Comp. Biochem. Physiol. 102: 251-255. 
JING X.H. \& KANG L. 2002: Research progress in insect cold hardines. - Acta Entomol. Sin. 22: 2202-2207.

JING X.H. \& KANG L. 2004: Overview and evaluation of research methodology for insect cold hardiness. - Chin. Bull. Entomol. 40: $7-10$.

LEE R.E. 1991: Principles of insect low temperature tolerance. In Lee R.E. \& Denlinger D.L. (eds): Insect at Low Temperatures. Springer, New York, pp. 17-46.

LEE R.E. 1989: Insect cold-hardiness: To freeze or not to freeze. - BioScience 39: 308-313.

LEE R.E. 2010: A primer on insect cold tolerance. In Denlinger D.L. \& Lee R.E. (eds): Low Temperature Biology of Insects. Cambridge University Press, Cambridge, pp. 3-34.

Lee R.E. \& Denlinger D.L. 1985: Cold tolerance in diapausing and non-diapausing stage of the flesh fly, Sarcophaga crassipalpis. - Physiol. Entomol. 10: 309-315.

LI Y.J. 2008: The occurrence and control of major pests of Pinus tabulaeformis in Liaoning Province. - Liaoning For. Sci. Technol. 3: 57-59.

Li X.P., Song L.W., Zhang H.H., Chen Y.Q., Zuo T.T., Wang J. \& Sun W. 2012: Responses of Arma chinensis cold tolerance to rapid cold hardening and underlying physiological mechanisms. - Chin. J. Appl. Ecol. 23: 791-797.

LI Y. 2013: Biology characteristic and prevention of Chinese pine larva aculeata. - Mod. Agric. Sci. Technol. 21: 165-167.

LI M. 2014: Comprehensive prevention and control technology of Dendrolimus. - Mod. Agr. Sci. Technol. 24: 21.

Li Y.P. \& Gong H. 2000: Insect cryobiology: II. Ice core material (ice core protein) and the frost resistance of insect. - Chin. Bull. Entomol. 37: 250-254.

Liu K.W. 2012: Sex Pheromone Identification of Chinese Pine Moth Dendrolimus tabulaeformis and the Release Rates of Pine Caterpillar Moths Pheromones from Dispensers. M.Sc. Thesis, Shandong Agricultural University, Shandong.

Liv S.H. 2006: The harms of Dendrolimus tabulaeformis and preventing methods. — Sci-Tech. Inform. Dev. Econ. 16: 285-286.

LiU Y.Q. 1963: A general survey of the geographical distribution of Dendrolimus germar in the eastern portion of China. - Acta Ecol. Sin. 12: 345-353.

Liu Z., Gong P., Wu K., Wei W., Sun J. \& Li D. 2007: Effects of larval host plants on over-wintering preparedness and survival of the cotton bollworm, Helicoverpa armigera (Hübner) (Lepidoptera: Noctuidae). — J. Insect Physiol. 53: 1016-1026.

Liu H., Yin H.J., Cheng X.J., Lin B., Zhao C.Z. \& Yin C.Y. 2010 Problems and strategies of sustainable regeneration of plantation ecosystem in China. - World For. Res. 23: 71-75.

Ma R.Y., Hao S.G., Kong W.N., Sun J.H. \& Kang L. 2006: Cold hardiness as a factor for assessing the potential distribution of the Japanese pine sawyer Monochamus alternatus (Coleoptera: Cerambycidae) in China. - Ann. For. Sci. 63: 449-456.

Ouyang F. \& Ge F. 2014: Determination and analysis of antifreeze and cold resistance of insects. - J. Appl. Entomol. 51: $1646-1652$

Ouyang F., Liu Z.D., Yin J., Su J., Wang C. \& Ge F. 2011: Effect of transgenic Bt cotton on overwintering characteristics and survival of Helicoverpa armigera. - J. Insect Physiol. 57: $153-160$

QIN J.M., Luo S.D., HE S.Y. \& Wu J. 2015: Researching in characters and functions of trehalose and trehalose enzymes in insects. - J. Environ. Entomol. 37: 163-169.

Rozsypal J., Koštál V., ZahradníčKová H. \& ŠImeK P. 2013: Overwintering strategy and mechanisms of cold tolerance in the codling moth (Cydia pomonella). - PLOS ONE 8(4): e61745, $11 \mathrm{pp}$.
Saeidi F., Moharramipour S. \& Barzegar M. 2012: Seasonal patterns of cold hardiness and cryoprotectant profiles in Brevicoryne brassicae (Hemiptera: Aphididae). - Environ. Entomol. 41: 1638-1643.

Sinclair B.J., Addo-Bediako A. \& Chown S.L. 2003: Climatic variability and the evolution of insect freeze tolerance. - Biol. Rev. 78: 181-195.

Sinclair B.J., Alvarado L.E.C. \& Ferguson L.V. 2015: An invitation to measure insect cold tolerance: methods, approaches, and workflow. - J. Therm. Biol. 53: 180-197.

Søмme L. 1982. Supercooling and winter survival in terrestrial arthropods. - Comp. Biochem. Physiol. (A) 73: 519-543.

Stephen R.M., Chen C.P. \& Virginia K.W. 2001: Cold tolerance and proline metabolic gene expression in Drosophila melanogaster. - J. Insect Physiol. 47: 393-400.

Storey K.B. \& Storey J.M. 1991: Biochemistry of cryoprotectants. In Lee R.E. \& Denlinger D.L. (eds): Insect at Low Temperatures. Chapman and Hall, New York, pp. 64-93.

Sun X.G., Mao X.H. \& Li S.T. 2001: The cold tolerance mechanism of insects and its research development. - J. Shandong Agr. Univ. 32: 393-396.

TANG W.G. 2012: Study on biological characteristics and comprehensive prevention and control technology of Dendrolimus tabulaeformis. - J. Shanxi Agr. Sci. 58: 47-49.

Wang X.H. \& Kang L. 2014: Molecular mechanisms of phase change in locusts. - Annu. Rev. Entomol. 59: 225-243.

WANG Q.S. \& WANG Y.Z. 2006: Study on the relationship between the damage of Dendrolimus tabulaeformis and stand three factors. - Protect. For. Sci. Technol. 2006(z1): 25-27.

Wang P., Yu Y., Men X.Y., Zhang S.C., Zhang A.S., Zhang Y.Y. \& Ling L.L. 2011: Dynamics of cold-resistant substances in overwintering cocooned and non-cocooned larvae of the peach fruit moth, Carposina niponensis Walsingham (Lepidoptera: Carposinidae). - Acta Entomol. Sin. 54: 279-285.

Wharton D.A., Young S.R. \& BarRetT J. 1984: Cold tolerance in nematodes. - J. Comp. Physiol. (B) 154: 73-77.

Williams C.M., Thomas R.H., Macmillan H.A., Marshall K.E. \& SinCLAIR B.J. 2011: Triacylglyceride measurement in small quantities of homogenised insect tissue: comparisons and caveats. - J. Insect Physiol. 57: 160-1613.

XIA R.X. \& XU L.H. 1993: Study on the super-cooling point of the overwintering larvae of three kinds of pine caterpillar. - Sci. Silva. Sin. 29: 186-189.

XIA N.B., Tu Q.H. \& MA Z.S. 1989: A study on sampling techniques for Dendrolimus tabulaeformis larvae. - Acta Ecol. Sin. 9: 341-347.

XIA N.B., Tu Q.H. \& Zhang S.F. 1990: Study on the dynamic pattern of Dendrolimus tabulaeformis larvae. - Sci. Silva. Sin. 26: $322-328$.

Xue J.L., NiU X. \& XIE Y.P. 2006: Changes of protein, esterase and PPO in Dentrolimus tabulaeformis infected by Beauveria bassiana. - Chin. J. Appl. Environ. Biol. 12: 814-818.

Yuan Y.Y., Gao B.J., Li M., Yuan S.L. \& Zhou G.N. 2008: The genetic diversity of Dendrolimus tabulaeformis in forests of different stand types. - Acta Ecol. Sin. 28: 2100-2106.

Zachariassen K.E. 1985: Physiology of cold tolerance in insect. - Physiol. Rev. 65: 799-832.

Zeng J.P., Ge F., Su J.W. \& WANG Y. 2008: The effect of temperature on the diapause and cold hardiness of Dendrolimus tabulaeformis (Lepidoptera: Lasiocampidae). - Eur. J. Entomol. 105: 599-606.

ZeNG J.P., GE F., Su J.W. \& HE Z. 2010: Researches on the occurrences of major forest insect pests of pine caterpillar Dendrolimus spp. in China. - Chin. Bull. Entomol. 47: 451-459. 
ZhaNG L.L. 2005: Study of Influence on Growth and Development of Dendrolimus tabulaeformis (Tsai et Liu). M.S. Thesis. Beijing Forestry University, Beijing.

ZHANG L.X. 2011: New progress in the study on spatial pattern of different instars population and sampling technique of Dendrolimus tabulaeformis. — Liaoning For. Sci. Technol. 6: 25-31.

Zhang Y.L., Mu W., Chen Z.L., Han Z.R., Ma C. \& Zhai R.H. 2007: Susceptibility and related physiological and biochemical mechanisms of Carposina niponensis Walsingham larvae on six insecticides before and after overwintering. - Chin. J. Appl. Ecol. 18: 1913-1916.
Zнао L.J. 2003: Study on Water Consumption Characteristics of Main Plantation Tree Species and Technology of Drought Resistant for Afforestation in North China. M.S. Thesis, Beijing Forestry University, Beijing.

Zhao J., Yu L.Y., Li M., Zheng F.Q., Zhang F. \& Xu Y.Y. 2008: Seasonal variation in cold tolerance of the multicolored ladybeetle, Harmonia axyridis (Pallas) (Coleoptera: Coccinellidae) adults. - Acta Entomol. Sin. 51: 1271-1278.

Zhu J., Zhang X.F., Yang W.B. \& Wang Z.M. 1995: Study on the damage mechanism and the influence to forest growth of Dendrolimus tabulaeformis. - Shaanxi For. Sci. Technol. 3: 36-39.

Received May 30, 2017; revised and accepted March 29, 2018 Published online May 2, 2018 